\title{
Coincident detection of lung metastasis of prostate cancer and primary lung cancer: A case report
}

\author{
Yusuke Muro, MD; ${ }^{*}$ Takeo Kosaka, MD, PhD, Tai Hato, MD, PhD; ${ }^{\dagger}$ Shuji Mikami, MD, PhD; \\ Mototsugu Oya, MD, PhD*
}

*Department of Urology, Keio University School of Medicine, Tokyo, Japan; †Department of General Thoracic Surgery, Keio University School of Medicine, Tokyo, Japan; §Division of Diagnostic Pathology, Keio University School of Medicine, Tokyo, Japan

Cite as: Can Urol Assoc J 2015;9(7-8):E524-6. http://dx.doi.org/10.5489/cuaj.2376 Published online July 17, 2015.

\section{Abstract}

We report an extremely rare case of 79-year-old man, who was discovered with coincidental lung metastasis of prostate cancer and primary lung cancer. The patient presented with low prostatespecific antigen and two lung lesions: one in the right lower lobe, and one in the right upper lobe, 3 years after he was treated with external beam radiotherapy for Gleason score $4+3=7$, cT3aNOMO prostate cancer. A computed tomography-guided needle biopsy of a nodule in the right lower lobe revealed suspicious metastasis of prostate cancer. Thoracoscopic excisions of both lesions were performed, and each lung lesion was diagnosed as being metastatic prostate cancer and primary lung cancer.

\section{Introduction}

Prostate cancer may metastasize to any organ, including bone, lymph node, and lung. Although lung metastasis has been reported in more than $40 \%$ of cases of prostate cancer, ${ }^{1,2}$ cases of isolated lung metastases without concurrent bone or lymph node metastases are limited. There have been some reports of isolated lung metastases of prostate cancer in the past, but none have reported solitary metastases and primary lung cancer discovered coincidentally. We describe a unique case of two lung lesions: one diagnosed as lung metastasis of prostate cancer and one as primary lung cancer after thoracoscopic resection.

\section{Case presentation}

The patient first presented with dysuria (International Prostate Symptom Score 16, Quality of Life 5) in 1995 and has been followed with an alpha-blocker since then with a diagnosis of benign prostatic hypertrophy. His prostate-specific antigen (PSA) level stayed around 7 to $8 \mathrm{ng} / \mathrm{mL}$; due to symp- tom progression, transurethral resection of the prostate was carried out in 2006, with no evidence of malignancy. He revisited our department with elevated PSA of $14.8 \mathrm{ng} / \mathrm{mL}$ in 2008, and needle biopsy of the prostate was performed. He was diagnosed with moderately differentiated prostate cancer, with Gleason Score of $4+3=7$ and cT3aNOMO (magnetic resonance imaging, chest-pelvic computed tomography [CT] scan and bone scintigraphy). External beam radiotherapy (EBRT) of $70 \mathrm{~Gy} / 35 \mathrm{Fr}$ was performed from July 2009, with concomitant combined androgen blockade (CAB). After PSA had reached its nadir $(0.04 \mathrm{ng} / \mathrm{mL})$ in October 2009 , it gradually started to increase. Because the patient expressed a strong desire for early treatment, $C A B$ was resumed when it reached $0.95 \mathrm{ng} / \mathrm{mL}$ in October 2011.

His PSA eventually dropped to $0.03 \mathrm{ng} / \mathrm{mL}$, but he was informed about an abnormal chest shadow at a routine checkup in June 2012. The patient had a 38-year history of smoking 7 cigarettes a day, and had a history of hypertension. A chest CT scan showed a $5-\mathrm{mm}$ nodule in the right lower lobe S8, and a ground-glass opacity (GGO) in the right apical portion (S1). The department of thoracic surgery was consulted, and because the S8 nodule increased its size to $8 \mathrm{~mm}$ after 5 months of serial imaging, a CT-guided lung biopsy of the S8 nodule was carried out. Metastasis of prostate cancer was suspected, with partially-positive PSA immunostaining.

A video-assisted thoracoscopic wedge resection for both right S1 and S8 lesion was performed in Februrary 2013 to confirm suspicious metastatic prostate cancer and to treat GGO in S1. The S1 lesion was diagnosed as primary lung cancer, and the immunostaining of S8 lesion revealed adenocarcinoma with CK7(-), CK20(-), TTF-1(+/-), PSA (+) and was diagnosed as metastatic prostate cancer. The postoperative course was uncomplicated, and the patient is currently under follow-up with no newly detected metastases. With continued use of luteinizing hormone-releasing hormone agonists, the patient's PSA has remained $<0.05 \mathrm{ng} / \mathrm{mL} 18$ months after surgery. 


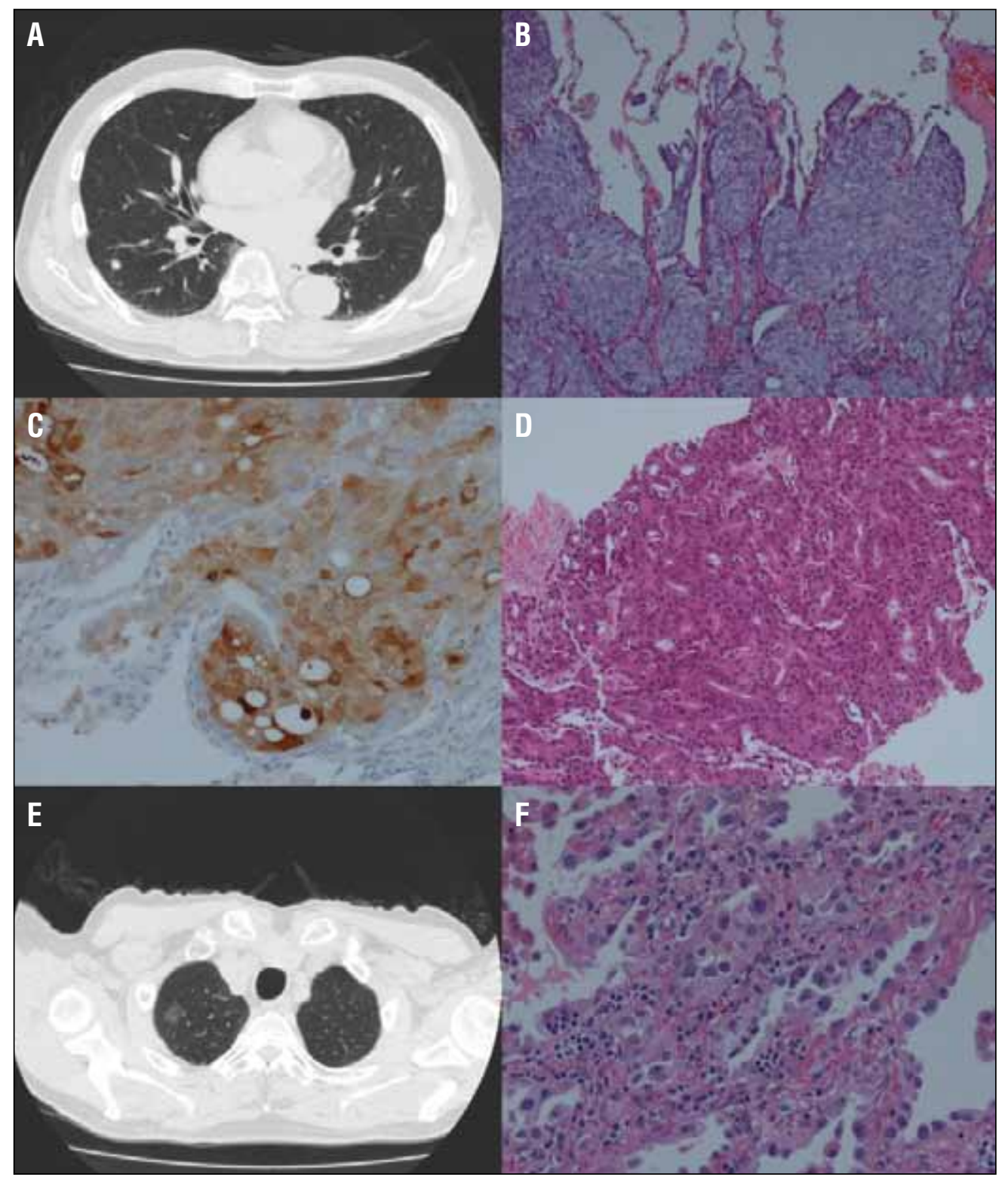

Fig. 1. A: A computed tomography (CT) scan showing $S 8$ nodule on right lobe. B: Resected specimen of S8 showed similar characteristics to the needle biopsy specimen of the prostate (hematoxylin and eosin [H\&E], $\times 100$ ). C: The positive prostate-specific antigen stain revealed metastasis of prostate cancer to the lung (PSA stain, $\times 200$ ). D: The original needle biopsy of Gleason Score $4+3=7$ prostate cancer $(H \& E, \times 100)$. E: CT scan showing a groundglass pattern in $\mathrm{S} 1$ of right lobe. $\mathrm{F}$ : Resected specimen showing primary lung cancer $(\mathrm{H} \& \mathrm{E}, \times 200)$. CT: computed tomography, PSA: prostate specific antigen.

\section{Discussion}

Lung metastases of prostate cancer are seen in some terminal patients with multiple metastases. However, isolated lung metastases, without concurrent bone or lymph node metastases, are extremely rare. It has been reported that isolated lung metastases are found in less than $1 \%$ of autopsy cases of metastatic prostate cancer. ${ }^{3}$ In a clinical study of 1290 patients diagnosed with prostate cancer, 48 patients had lung metastases, with only 11 patients $(0.86 \%)$ having solitary nodule. ${ }^{4}$ There have been several reports of isolated multiple pulmonary metastases; ${ }^{5}$ however, none have reported lung metastases of prostate cancer and primary lung cancer detected at the same time. Our case is the first to present these unique characteristics.

The most conventional treatment option for metastatic prostate cancer is androgen-deprivation therapy, but pulmonary metastatectomy is an option for isolated lung metastases 
Muro et al.

without bone and lymph node involvement. Both surgical excision and androgen-deprivation therapy have resulted in some regression or resolution of pulmonary nodules. ${ }^{5}$ It was reported, in a case report, that the resection of a solitary lung metastasis of prostate cancer resulted in 12 years of biochemical remission without additional therapy. ${ }^{6}$ These findings suggest that although lung metastases are usually regarded as a manifestation of systemic disease, their early removal may be a management option for prostate cancer patients with pulmonary nodules.

The National Comprehensive Cancer Network guideline recommends radiologic surveillance for pulmonary nodules less than $8 \mathrm{~mm}$, and either biopsy or surgical resection for nodules over $8 \mathrm{~mm}$ with either biopsy or surgical resection. ${ }^{7}$ In our case, because two intrathoracic lesions were ipsilateral, we decided to resect the S8 lesion as diagnostic therapy and at the same time resect $\mathrm{S} 1$ lesion to treat possible lung cancer. PSA following metastatectomy remains undetectable, but long-term follow-up is needed as there are studies reporting a high incidence of recurrence following lung metastatectomy. ${ }^{8}$

In our case, chest imaging was not performed after PSA started showing an upward trend after EBRT and CAB; therefore, it is hard to speculate when the lung metastasis first appeared. However, PSA was at its maximum level of only $0.95 \mathrm{ng} / \mathrm{mL}$ after EBRT, so it can be said that the prostate cancer metastasized to a distant organ while the PSA level was low. Metastatic prostate cancer patients with PSA less than $10 \mathrm{ng} / \mathrm{mL}$ are almost always poorly differentiated or undifferentiated. ${ }^{9}$ The type of differentiation in our case was moderately differentiated at the time of prostate needle biopsy, but it may have changed during the course of treatment.

\section{Conclusion}

We present a rare patient with prostate cancer with low PSA, who was diagnosed with a solitary lung metastasis and primary lung cancer at the same time, without concurrent bone or lymph node metastases. Complete excisions of both lesions were carried out. Monitoring PSA for the follow-up of prostate cancer patients has limitations. Although lung metastases are not common, our case demonstrates that chest imaging plus a tissue diagnosis can lead to a surgical resection as a way to treat prostate cancer patients with pulmonary nodules.

Competing interests: The authors all declare no competing financial or personal interests.

This paper has been peer-reviewed.

\section{References}

1. Bubendorf L, Schopfer A, Wagner U, et al. Metastatic patterns of prostate cancer: An autopsy study of 1,589 patients. Hum Pathol 2000;31:578-83. http://dx.doi.org/10.1053/hp.2000.6698

2. Vinjamoori AH, Jagannathan JP, Shinagare AB, et al. Atypical metastases from prostate cancer: 10-year experience at a single institution. AJR Am J Roentgenol 2012;199:367-72. http://dx.doi.org/10.2214/ AJR. 11.7533

3. Saitoh H, Hida M, Shimbo T, et al. Metastatic patterns of prostatic cancer. Correlation between sites and number of organs involved. Cancer 1984;54:3078-84. http://dx.doi.org/10.1002/10970142(19841215)54:12<3078::AID-CNCR2820541245>3.0.C0;2-U

4. Fabozzi SJ, Schellhammer PF, el-Mahdi AM. Pulmonary metastases from prostate cancer. Cancer 1995;75:2706-9. http://dx.doi.org/10.1002/1097-0142(19950601)75:11<2706::AlDCNCR2820751111>3.0.C0;2-Y

5. Wallis $(J$, English JC, Goldenberg SL. The role of resection of pulmonary metastases from prostate cancer: A case report and literature review. Can Urol Assoc J 2011;5:E104-8. http://dx.doi.org/10.5489/ cuaj.10136

6. Chao DH, Higgins JP, Brooks JD. Biochemical remission after resection of prostate cancer lung metastasis. Urology 2004;63:584-5. http://dx.doi.org/10.1016/i.urology.2003.10.069

7. Ettinger DS, Akerley W, Borghaei H, et al. National comprehensive cancer network. Non-Small Cell Lung Cancer, Version 2. 2013 J Natl Compr Canc Netw 2013;11:645-53.

8. Laisaar T, Vooder T, Umbleja T. Thoracoscopic resection of a solitary pulmonary nodule in patients with a known history of malignancy. Thorac Cardiovasc Surg 2008;56:418-21. http://dx.doi. org/10.1055/s-2008-1038347

9. Yamamoto $\mathrm{S}$, Ito $\mathrm{T}$, Akiyama $\mathrm{A}$, et al. $\mathrm{Ml}$ prostate cancer with a serum level of prostate-specific antigen less than $10 \mathrm{ng} / \mathrm{mL}$. Int J Urol 2001;8:374-9. http://dx.doi.org/10.1046/i.1442-2042.2001.00316.x

Correspondence: Dr. Takeo Kosaka, Department of Urology, Keio University School of Medicine, 35 Shinanomachi, Shinjuku-ku, Tokyo 160-8582, Japan; takemduro@a6.keio.jp, takemduro@gmail.com 